\title{
Hot news from summer 2003
}

\author{
Christoph Schär and Gerd Jendritzky
}

\section{The European heatwave of 2003: was it merely a rare meteorological event or a first glimpse of climate change to come? Probably both, is the answer, and the anthropogenic contribution can be quantified.}

$\mathrm{T}$ he European summer of 2003 was characterized by highly anomalous meteorological conditions ${ }^{1}$, and was extremely hot and $\mathrm{dry}^{2,3}$. In the northern parts of the continent, the summer was perceived as beautiful and warm. But in central and southwestern Europe, the heat was prolonged and intense, and the economic and societal consequences were disastrous (as described in Box 1).

Given the heatwave's severe repercussions, the question has arisen whether the summer of 2003 is evidence of man-made climate change. On page 610 of this issue, Stott, Stone and Allen ${ }^{4}$ take a major step towards answering this difficult question. Previous studies had found that recent changes in the European summer climate were consistent with climate-change scenar$\operatorname{ios}^{5,6}$, but there had been no attempts at a rigorous attribution of cause and effect. Indeed, because the atmosphere is a chaotic dynamical system, it is impossible to attribute - in a causal sense - an individual episode of extreme weather to changes in atmospheric composition. Nevertheless, it is feasible to estimate the probability or risk of occurrence of a certain weather event under natural and modified climatic conditions. This is the avenue taken by Stott and colleagues.

Using one of the leading global climate models available, the authors derive the probability distributions of European summer temperatures for two sets of climate simulations, each covering the period since 1900 . The first set accounts for the past effects on climate that were due to variations in solar and volcanic activity, as well as to man-made influences (including increases in greenhouse-gas concentrations). The second set mimics a natural climate by prescribing natural factors alone. Stott and colleagues then calculate the changed risk of extremely hot summers that is attributable to past anthropogenic emissions of greenhouse gases, using a comparison of observed and simulated summer temperatures to account for uncertainties in man-made warming and natural variability. They find, at a confidence level of greater than $90 \%$, that more than half of the risk of 2003-like extreme European summers is attributable to human influences on the climate system.

Methodologically, Stott and colleagues ${ }^{4}$ use an approach developed for detecting global climate change and attributing causes to the changes identified. There is long experience with such studies, all of which find that a significant anthropogenic contribution is required to explain the observed global climate records of the past 30-50 years ${ }^{7,8}$. The new study fits into these results, as the probability of extreme heatwaves must change as mean temperatures increase. The details of the analysis are rather complex. But the basic interpretation of the main result is comparatively straightforward: anthropogenic warming shifts the statistical distribution of summer temperatures towards warmer conditions, and this has a dramatic impact on the chance of temperatures exceeding some threshold out in the upper tail of the temperature distribution.

What about the limitations of the new work? We will mention two. First, Stott et al. address the whole summer of 2003 (and not the extreme heatwave in early August), and all of continental and southern Europe (not the much smaller central European region where the heatwave was most intense). Consideration of shorter-term and smallerscale heatwaves will require higher computational resolution ${ }^{9}$, and will need to take the complexities of land-surface processes into consideration $^{1,3}$. Accounting for these factors is a challenge. Second, representing natural climate variability is a general difficulty in studies attempting to attribute causes to particular effects. Stott et al. show that their model appropriately represents the spectrum of continental-scale European climate variability on interannual to interdecadal timescales. But more detailed

\section{Box 1 Impacts of the heatwave}

According to reinsurance estimates, the drought conditions during the summer of 2003 caused (uninsured) crop losses of around US\$12.3 billion, while forest fires in Portugal were responsible for an additional US\$1.6 billion in damage. The European electricity markets reacted erratically to increases in demands, as power plants had to curtail production owing to the lack of cooling water, and electricity spot prices soared beyond $€ 100$ (\$130) per MW h. In the Alps, many glaciers underwent unprecedented melting, and the thawing of permafrost led to a series of severe rock falls.
But it was the unusual number of deaths during 1-15 August that caught the headlines. Estimates based on the statistical excess over mean mortality rates amount to between 22,000 and 35,000 heat-related deaths across Europe as a whole ${ }^{11}$. In France the mortality rate increased by $54 \%$ during those two weeks, and the increase was statistically significant in all 22 French regions and for all age groups above 45 years $^{12}$.

The figure, reproduced from ref. 13 , shows the daily mortality rate in Baden-Württemberg, Germany, over a period of 20 months, and puts the August

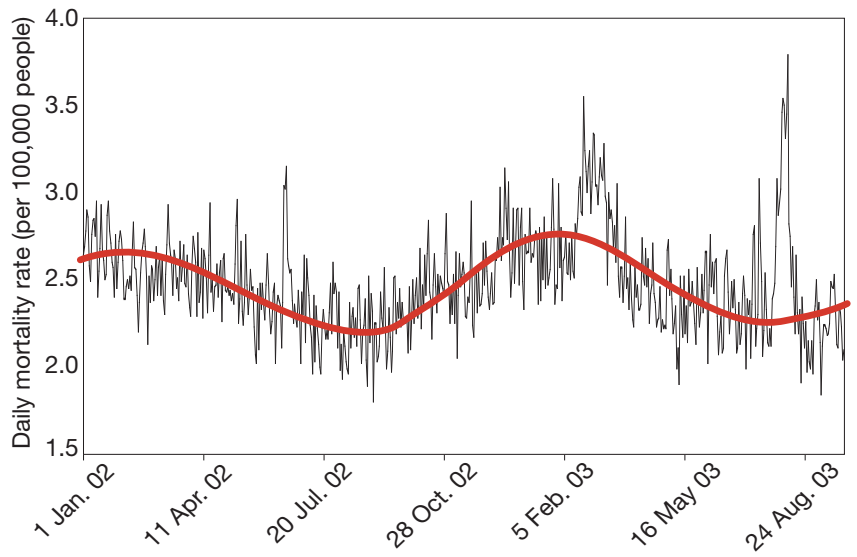

2003 heatwave in context. Total daily mortality data are in black, with the mean seasonal evolution in red. Notable features are the seasonal cycle, with higher mortality in winter; a heat-related mortality peak in June 2002; the effects of an influenza outbreak in February-March 2003; and the striking peak in August 2003, due to the heatwave, which caused 900-1,300 extra deaths in a population of 10.7 million people.

C.S. \& G.J. 
studies will be needed to corroborate this conclusion, as there are large uncertainties in the estimates of natural climate variabilityderived from both models and observations ${ }^{8}$.

Nonetheless, Stott and colleagues' work constitutes a breakthrough: it is the first successful attempt to detect man-made influence on a specific extreme climatic event. Such events are among the most notable features of a changing climate, not least given their impact on human affairs. Another article in this issue, by Allen and Lord (page $551)^{10}$, discusses how refined analyses might lead to liability claims for costs incurred by climatic shifts. The advent of such 'attribution studies' might profoundly affect the course of international negotiations on ways to mitigate, adapt to and ultimately pay for the consequences of climate change. Christoph Schär is at the Institute for Atmospheric and Climate Science, ETH, Winterthurerstr. 190, 8057 Zürich, Switzerland. e-mail: schaer@env.ethz.ch

Gerd Jendritzky is with the German Weather

Service, Human Biometeorology,

Stefan-Meier-Str. 4, D-79104 Freiburg, Germany.

e-mail: gerd.jendritzky@dwd.de

1. Black, E., Blackburn, M., Harrison, G., Hoskins, B. J. \& Methven, J. Weather 59, 217-223 (2004).

2. Luterbacher, J. et al. Science 303, 1499-1503 (2004).

3. Schär, C. et al. Nature 427, 332-336 (2004).

4. Stott, P. A., Stone, D. A. \& Allen, M. R. Nature 432, 610-614 (2004).

5. Pal, J. S., Giorgi, F. \& Bi, X. Geophys. Res. Lett. 31, L13202 (2004).

6. Meehl, G. A. \& Tebaldi, C. Science 305, 994-997 (2004).

7. Hegerl, G. C. et al. J. Clim. 9, 2281-2306 (1996).

8. Mitchell, J. F. B. et al. in Climate Change 2001: The Scientific Basis (eds Houghton, J. T. et al.) 605-738 (Cambridge Univ. Press, 2001).

9. Christensen, J. H. \& Christensen, O. B. Nature 421, 805-806 (2002).

10. Allen, M. R. \& Lord, R. Nature 432, 551-552 (2004).

11. International Federation of Red Cross and Red Crescent: World Disasters Report www.ifrc.org/publicat/wdr2004/chapter2.asp

12. Hémon, D. \& Jougla, E. Surmortalité liéé à la canicule d'août 2003 (INSERM, Paris, 2004); www.inserm.fr

13. Koppe, C. \& Jendritzky, G. in Gesundheitliche Auswirkungen der Hitzewelle im August 2003 (Sozialministerium Baden-

Württemberg, Stuttgart, 2004); www.gesundheit-bw.de/ download/bericht_gesundh_auswirkungen.pdf 